\title{
From a common concept to common experimentation? The water framework directive's impact on water management in Europe
}

\author{
P. Canelas de Castro \\ University of Macau, China, University of Coimbra, Portugal
}

\begin{abstract}
There is no doubt that the European Union has a water policy. This policy, stemming from the early 1970s, stands as a forerunner of its environmental policies. It translated into an impressive number of legal documents, leading most commentators to speak of several waves of European legislation. Prior to the adoption of the Water Framework Directive in 2000, this policy had several shortcomings which hindered its successful implementation and the reversal of the bad quality of European water. Europeans even elected the pollution of water as their most serious environmental concern. The Water Framework Directive promises to break up with this poor record by introducing new solutions to old problems. These amount to a paradigm shift in the conception of water management and its actual implementation. In our article we propose to analyze the main pillars of this new conceptual construction of European water management, looking in particular at key solutions such as the election of the river basin as the geographical reference of the regime, the setting of innovatory goals, such as those of good water status and environmental objectives presiding over both the qualitative and quantitative dimensions of water management, the resorting to management plans and programmes of measures to discipline the actions seeking good water status, the combined approach as the new method to handle pollution control, the opening to very wide public participation in water management. We shall equally endeavour to assess the practical relevance of these solutions for a new water management in Europe. Moreover, we shall seek to characterize the efforts at ensuring a common implementation of this normative programme, aimed at giving the European citizens waters of satisfying
\end{abstract}


quality and capable of ensuring sustainable development in conditions of climate change.

Keywords: common implementation strategy, cost recovery, economic incentives, European community, European union, experimentation, experimental governance, good water status, integrated river basin management, new governance, paradigm-shifts.

\section{Introduction}

Water is important and even vital for the life or health of both humankind and ecosystems. It is also a factor conditioning development and civilization. Additionally, many cultural, religious and aesthetic expressions are also associated with water.

In the EU, water only turned into a legal subject matter when it became a problem. The Romans, excellent lawyers, had already called our attention to this 'natural law' - Ius oportet ut scandala eveniant: Law is created when scandals intervene. The scandal determining the creation and policy development of European Water law emerged from the apprehension that the European waters were not in a good state. This, and the realization that the States of the EU traditionally competent to manage the water in their territories - were not meeting the expectations of their citizens who were highly worried. Indeed, EU surveys have persistently demonstrated that the single most recurrent environmental concern of the Europeans is water pollution, consistently as high as almost $50 \%$ of those polled.

Faced with this scenario of crisis and the additional concern that any regulation protecting the environment should not harm the construction of the internal market, the EU, then the EEC, started to devise and implement a water policy. This one, which was born with the $1^{\text {st }}$ Environmental Action Programme in the early $70 \mathrm{~s}$, has actually become one of the oldest EC environmental policies. The EU exercised its role through water legislation and, to a much lesser extent, through constitutional rules adopted after the Single European Act in 1986.

Over the years, the development of this Policy and corresponding legislation has been steady. So much that observers have identified two waves of legislation up to the mid 90s (Canelas de Castro [1-3]). The mid 90s, however, represent a breaking point whereby a fundamental rethinking of the policy took place. The result was the adoption of the WFD in 2000, after a notorious tug of war between the European Parliament and the Council of Ministers. Ever since, we have been in the $3^{\text {rd }}$ age or wave of this policy and law.

As relatively old as this policy is, it is, however, also very young at heart. It has been especially rejuvenated with the WFD, gaining new life and momentum which it continues to demonstrate in the documents which have been adopted since 2000 (in particular, those relating to the Common Implementation Strategy, firstly adopted in 2001 and the many different Directives adopted ever since, on priority substances, on groundwater, on the marine policy). This has materialized 
in not only an impressive number of changes but also in a fundamental, radical change in quality which needs to be underlined.

In this article we propose to briefly map out these mutations and subsequently try to assess their significance and potential. For this, a contrast between the former waves of legislation and the one initiated with the WFD shall be endeavoured, focusing on the comparison of the WFD-initiated wave with the former waves (which are taken together, overlooking the differences), particularly in terms of the object of the policy, the environmental density thereof, the economic awareness of such a policy, and its presentation of relevant subjects.

\section{Object}

The object of the initial stages of the EU Water Policy was disparate and fragmented - the policy only versed over some waters; usually waters of purely or mainly human interest, such as waters for drinking purposes, waters for bathing, and waters for shellfish production. The underlying perspective was anthropocentric only and there was no such thing as an integrative vision of the whole system.

The newer EU Water Policy, is on the contrary, determined to capture Nature as it is, namely in its units, but also in its wholeness and complexity as well as the intricate web of corresponding problems (art. 1). Accordingly, the river basin is chosen as the geographical unit for the substantive regime which it sets out. All the waters which naturally come together are thus included, be they ground, surface, estuarine or coastal waters, as well as depending ecosystems, because waters are indeed also intertwined with ecosystems. This is the more remarkable as, for that, this newer Water Policy is ready to ignore the traditional criterium of a human policy, that of political and administrative entities. On the contrary, it prescribes that these administrative units follow this approach of respect and attention to reality and, on that basis and for that aim, they have to coordinate, cooperate - these later ones being precisely some of the fundamental obligations of the regime (art. 3).

This attention to reality and real Nature is also reflected in the consideration of the reality of the problems which impact and affect waters. The range of management or subject matters covered extends from pollution to costs of actions, comprehends both quality and quantity issues, focuses on planning but also looks at extreme events. Holism (of subject matters, issues and their normative treatment) goes together with integration (of waters).

\section{Environmental friendliness}

The second characteristic of note of this policy is its clear environmental friendliness. As much as this note may look surprising, at first look, the EC Water Policy being, from the start, part of EC Environmental Policies, the fact is that, in the past, environmentalism was more proclaimed than real. Of course, the EC did - at the time - intervene to protect waters, but the construction of the 
internal market was the real compelling driver, mainly an economic one. Added to the fragmentary vision of waters and the marked anthropocentrism of this younger phase, the EU Water Policy was one of very shallow environmentalism.

The $3^{\text {rd }}$ wave, on the contrary, makes a clear, resolute choice for a more radical protection of the environment, as is evidenced in several factors: besides the already mentioned river basin reference to the apprehension of reality of all waters, and the ecosystems; and the relative irrelevance of administrative criteria in the shaping of the policy, foremost, the centrality of its environmental objectives (Art. 4 of the WFD) and, even more, its proclaimed principal goal: that of attaining good water status by 2015 (art. 1). This option becomes even clearer when the criteria to good water status is apprehended: ecological, along with chemical ones. This newer Water Policy clearly adopts an environmentally deep, sometimes even ecological and ecosystemic approach. This is equally confirmed by the adoption of the combined approach in the struggle against pollution as well as all the many principles that are detectable in its main legal text - those of prevention, precaution, minimization of impacts, typical environmental principles, sometimes even principles of ecological protection.

Overall, however, this option may still be seen as a deepening of a long lasting environmental option.

\section{Resort to economic instruments}

Nothing of the kind happens with the $3^{\text {rd }}$ vector characterizing this newer Policy - that of bringing in the economy. This is a first, a radical innovation in itself.

This option translates into two main principles and corresponding obligations with far reaching consequences. On the one hand, it asks for a full recovery of the costs of water services (Art.9); on the other hand, for the economic analysis in terms of costs and benefits of any measure undertaken (Art.5). Both have farreaching consequences, both represent a radical departure from the past.

Indeed, in the past, water was generally taken for granted. In the first two waves of water legislation, there was the recognition that there was a problem of water quality at the European level, but never that water was equally scarce and that, in some European regions in particular, a water quantity problem or crisis was looming. With its ground-breaking recognition by the WFD, obligations of attaching a value, a price-tag to water, and water services were also introduced.

This does not mean, of course, that in the past the compliance with the then applicable water policy lacked economic impact. For instance, the Wastewater Treatment Directive has brought about enormous investment in setting up waste water treatment plants throughout Europe. But these costs were not truly assessed.

The WFD rejects such a vision. Everyone has to be aware of the costs of water services, so as to better derive a social consensus on the hard choices to make. Furthermore, these costs have to constitute all the costs, costs of utilization (user-pays) but also costs of cleaning up the pollution created (polluter-pays). Environmental costs and services have to be accounted for, no matter how difficult this operation shall be. Moreover, there is also the obligation 
to assess the cost of measures undertaken, so as to enable truly rational decisionmaking. Action is necessary, indispensable even; but because it is so important, it has to be founded on sound information, on an accurate compilation and assessment of all relevant data. This economic, totally new, learning appears to be premised on a vision where the use of market instruments and (the protection of) the environment are portrayed as harmonious and converging: prices are depicted as instruments to induce a more rational usage of water, to avoid waste, encourage conservation and contribute to the hard deliberative decision-making ahead.

\section{Friendliness to inclusive relations}

This brings us to the fourth cardinal option of this newer Water Policy; that of promoting inclusive relations, the active participation of many stakeholders in the complex and vast process of water management.

This option is already very clear in the WFD. But it became even more obvious and resolute in later stages and particularly in the documents devising the so-called Common Implementation Strategy (CIS), a Strategy set out by Member States and the European Commission to govern the implementation of the WFD, an unusual initiative undertaken in 2001, without any normative binding base thereto, but instead premised on the recognition of the difficulties involved in such a process.

In the past, the subjective interplay corresponding to the implementation of the EC Water Policy was, overall, quite simple. The "game" or "scene" was initially inhabited by a small number of actors who would relate to each other in typically simple, dual, binary relations; moreover, the relations obeyed a hierarchical principle.

There were few actors: typically, the EU, first, which was charged with producing the Law and, if necessary, enforcing it; second, the Member States, which had the competence to implement such a policy; and, third, the undertakings (industrial corporations only, in the first wave; the agricultural and municipal sectors also, in the second wave) which were expected to abide by the standards imparted and seek permits, authorizations, licenses and concessions for undertaking some economic endeavors with potential consequences on waters.

As an expression of such simplicity, the typical relationship in the sector was also dual, with rigid, formal positions - competences - and actually a kind of zero-sum game where the entitlement of one actor to intervene was the lack thereof of another. Hence, the European institutions - not the States - were expected to establish the standards. Just as the States - not the EU - were expected to implement them. This game also assumed a principal-delegate mode: the EU knew better and knew everything regarding the protection of the environment, so is befell upon it to create the standards; whereas the delegate, the Member States, would pursue their implementation vis-à-vis their equally subordinate civil societies. Very rigid, very hierarchical; the social world lived aside; it was not part of the picture of the subjects of EC Water Policy. The newer EU Water Policy's narrative is a different one. 
First, it is the story of the emancipation and relevance of civil societies, henceforth entitled and urged to participate. Second, it is a story of very active, manifold relations, plurilateral as well as multilevel relations. Moreover, even the "old" actors, which of course do not disappear from the picture but instead maintain a leading position, are henceforth expected to intervene in different relations, sometimes with different vests.

Several reasons make the case for bringing in new actors; three, in particular: experience demonstrated that the old management, based on the Modernity underpinnings, on the aggressive capacity of a performing State, was a failure. The condition of waters deteriorated instead of ameliorating. Moreover, it was found that States, their bureaucracies in the (distant, aseptic) capitals, knew, after all, too little. Good management supposes good information, knowledge about the Europeans' rivers, groundwaters, lakes, the ecological processes, about the way in which water interacts with the chemical cocktail produced by the industries and dumped into the water bodies as waste, about floods and natural cycles of waters - because waters move constantly! Many times it is actually the modest peasant, living next to the river and with the river as well as from the river, who knows better. But he was not in the picture of the past!... In order to overcome this information deficit by pooling information, knowledge, a much broader universe of subjects has to be incorporated. In the process, these new actors also acquire legal positions, entitlements and voice, based on their expertise. Individuals, civil societies, NGOs, associations of users, epistemic communities, stakeholders, all are called to participate and contribute to the difficult task of water management.

The second reason is that management - integrated river basin management (IRBM) - shall equally contend with many interests and, not rarely, involve hard choices. IRBM is supposed to ascertain the views of peasants as well as the representatives of the domestic sector, industries as well as those of power generation, navigation. And sometimes it will involve sacrifices, for instance by establishing that some may not operate, fish, bath, cool turbines, flush waters, dump wastewaters in certain conditions, for the sake of others and the overriding goal of good water status. It was found that to build such consensus, to make difficult but legitimate choices, all those potentially affected, the stakeholders, should be granted some kind of voice.

The third reason has to do with the fact that this policy is devised to be pursued, implemented and, if necessary, enforced. The newer Policy has this acute sense of implementation, dynamic but also realistic implementation. But, then who is going to be the watchdog of respect for the standards? Brussels and its officials, even the Member State national ones, are too far away. Moreover, this is a policy which is demanding and which, for that reason also, will generate considerable costs - in investments, in pricing the water services. Who is going to foot the bill in a context where the European welfare State appears weakened? The implicit response is that other entities, the individuals, undertakings, private capitals, be it in public-private partnerships, have to be brought into this picture as well. And indeed, in the CIS, all of these actors are going to find a seat in the 
evolving process, in the driving vehicle of the flexible, informal structure which orients this process of Common Implementation.

Moreover, this also happens, with the old actors; in newer terms, though. Their relations are also framed in different ways.

This can be seen first with the EU and is in part a consequence from the constitutional evolution of the EU. Whereas in the past, the Council of Ministers had a clearly prevailing hand, this is no longer the case after Amsterdam, Nice and, shortly, Lisbon. Now it has to share the driving seat, on equal terms, with the European Parliament, which caters precisely to more diffuse and environmental-friendly interests, and which did not hesitate in making all its new weight felt in the dramatic protracted process leading to the adoption of the WFD - the first instance, it may be recalled, of a conciliation within the co-decisionmaking procedure. Furthermore, as was demonstrated by the adoption of the WFD but was made clearer by the CIS, there are increasingly also, at the European level, other bodies which are intervening, equally catering to other interests - such as the Committee of the Regions and the Economic and Social Committee. As to the Commission, it is playing a more active role, but also one of a less imperial nature, as the use of the term "partnership" in the dealings with the States increasingly conveys. Indeed, in the context of the CIS, the idea is to, more and more, overcome the static entrenchment of legal positions and adversarial-type competences and have all these governmental actors work together in the pursuit of the common but ambitious goal of attaining good water status by 2015. The idea in the CIS process is to have all relevant actors join hands, pool capacities, to prevent or avoid the need for adversarial enforcement, and jointly cooperating in the operationalising of the demanding common substantive programme.

Member States also evidence a different position. Not only have a few given up attempts at toppling down the whole joint mechanism by trying to construe art.175, paragraph 2 of the EC Treaty so as to allow (them) veto power (as results from Case C-36/98, Spain v. Council of Ministers, and the ensuing amendment of the "constitutional" text by the Treaty of Nice), but they have also given up the static reading of competences which, empowering all of them to care about implementation, in fact excused them from engaging in cooperation exercises; with the ultimate result, of course, that the compliance record was generally very poor indeed. This shows, first, as already pointed out, in them having devised the CIS, together with the Commission, where they steer and work together in operationalising the substantive regime. This explains subsequently - the flow of communication, materialized in reporting activities and their submittal to other States and the Commission, and the openness to then assess them collectively, in an original peer-review process and allowing the Commission to, on that basis, draw benchmarks of best practices and scoreboards as well as comment on the performances obtained, in a mutually learning and mutually improval process which ultimately gives way to setting up guidance documents destined at further assisting all of the components to improve the common work. 
Most obviously, a new balance between the EU and the Member States is thus struck, one which overcomes the static trench-like camps of each type of actor, in a process which thus was more akin to a battlefield. A new balance that, in a way, even overcomes the very notion of the problem conveyed by the WFD. The balance is now no longer one of a hierarchical principal-delegate model, but instead one of shared experimental governance. As such, States currently enjoy very wide freedom in the operationalization of the indeed very broad and undetermined concepts, but clear goals set out by the WFD. Against being awarded this freedom, the States are however to follow procedural duties of informing, reporting and engaging together with the EU Commission in that dynamic "game" of steady peer-review and feeding back the results into the system - an ever renewed system. Overall, this constitutes very much a constant learning (mutually learning) process. In a way, it also ensures that the administration has its own discretion and creative space. Sometimes, with an impact even on legislation, with the capacity to remaking this latter one (one of the functions of the art. 21 comitology procedure of the WFD), in this very openended process of translating Law into facts and always improving.

Another innovative strand is that States also interact amongst themselves. In the past, indeed, this did not have to happen, since each one was competent to implement the EU regulatory body in its own space. Instead, in the strategic Common Implementation, they are expected to report on their findings amongst themselves, compare them, and mutually assess and reinvent the standards - a need deriving from the vague, broad departing notions as well as the perception that greater knowledge needs to be obtained.

But there is more to it, because many of the European waters are shared waters, natural units artificially divided amongst many political entities. A need to cooperate thereby emerges, a need to coordinate views and activities, particularly in planning (as art.3, para.3 of the WFD stipulates).

Thus, new types of relations, still relating to States, but now also amongst States ensue, ones which even attain States other than Member States. Indeed, the intervention of States in this newer picture - it rather becomes a movie, an animated picture!- is henceforth not limited to Member States anymore. Rather, it also comprehends other States. Sometimes, in an "inferior" position, since they feel compelled to harmonise their laws to EU standards. But other times, other states even become leading parties in the construction of the regime. So much so that the borders between the EU and the outside seem to become blurred. European Union law in a way also integrates or becomes intertwined with International Law (for analogous moves on the part of International Law, particularly in other regional settings, see Canelas de Castro [4]). Indeed, article 3 of the WFD, urges for the taking into account of the international experience of International river basin commissions. The trend is epitomized by the realization that Norway - the European Economic Area State which twice rejected the Union! - was amongst the creators of the CIS in 2001!

And then there are also those relations within the State. Indeed, a new level of actors and relations is added under the WFD which did not exist before. In asking for the management to be referred to river basins, in prescribing that they 
give way to river basin districts and authorities (art.3, para.1), the WFD also opens the door to relations at the sub-national level. Coordination amongst the different authorities within a basin has to be established. For these authorities to make the requisite river basin plans and report to the national authorities, they shall have to consult widely with the public.

The whole process established by both the WFD and attendant directives as well as all the CIS leading documents is thus one of a very dense and intricate web or network of multiple relations.

There are relations which have predominantly a "vertical" orientation, but still at a multi-level which surpasses the old, simply dual model. As there are relations which take place predominantly over a horizontal axis. Some others seem to have both. Furthermore, some are squarely within the European Union realm, while others overflow into a more typical international context.

The whole complex of relations is plurilateral. As plurilateral as the informal "organization" which polarizes this set of relations in the so-called Common Implementation Strategy process. This one recalls the Open Method of Coordination as initially established in the Lisbon Council of 2000 and possibly better represented in the European Employment Strategy.

But what is possibly even more relevant is that such a process and corresponding informal Organization are persistently in flux, in a commendable effort of adaptation and updating to circumstances and times. There is thus a regular reinvention of the positions held and the relations maintained over time, according to work plans which attempt to capture the priorities of the moment.

\section{Assessment: paradigm shifts}

These changes are prolific. Moreover, they are momentous. Not rarely and particularly in the substantive options which have been noted, they involve different models of thinking, silent but effective revolutions in the management of waters. They may thus be termed paradigm shifts (Kuhn [5]).

The fundamental change that these developments bring about is one of the "philosophical" premises and orientation of this newer Water Policy. Whereas the older Water Policy appeared mainly as a technocratic set of different technical recipes for different, isolated problems, the newer Policy is a clear, coherent, substantive, procedural, organizational normative construction, founded on socially approved ethical underpinnings and teleological structural options.

Three options or friendships stand out in particular: the environmental one, the economic one, the one of social inclusion. These three pillars, associated with another sense of time, clearly represented in the working schedule foreseen by the WFD for the implementation of the core obligations or in the fact that the central instrument of river basin management planning is to be cyclically performed or updated - every six years (art. 13) - show that this is a policy aimed at the sustainable development of water, instead of the prior disparate and fragmentary protection or usage of isolated actions. It is moreover facilitated, embodied by a different, both more complex and plural vision of Law. 
This being said, and as is also typical of any paradigmatic shift, the fact that we can denote many innovations of profound impact, does not mean that in this newer law and policy they do not coexist with older elements. The newer model does not exist in a "pure" state. As well, it stands to be seen whether these elements modeling the newer Policy shall manage to find sufficient ground, roots in reality. Being, as it is, a very ambitious, normative-driven policy, it shall certainly need time to overcome the resistances of reality.

\section{References}

[1] Canelas de Castro. P., Novos Rumos do Direito da Água: a caminho de uma revolução (tranquila)?, Revista do Centro de Estudos de Direito do Ordenamento do Urbanismo e do Ambiente, No. 1, pp. 11-36, 1998.

[2] Canelas de Castro. P., European Community Water Policy (Chapter 14). The Evolution of the Law and Politics of Water, eds. J. Gupta and J. Dellapenna, Berlin, Springer, pp. 227-244, 2009.

[3] Canelas de Castro. P., The Global Challenge of Sustainable Water Management: International and European Union Law Responses. Temas de Integração, No. 25, pp. 95-133, 2008.

[4] Canelas de Castro. P., Recent Developments in Water Law, Principles and Comparative Cases, Lisbon, Luso-American Foundation, 2005.

[5] Kuhn, T., The Structure of Scientific Revolutions, Chicago, University of Chicago Press, 1962. 